\title{
Uses of magnesium sulfate in anesthesiology
}

\author{
Claudia I. Gutiérrez-Román ${ }^{1 *}$, Orlando Carrillo-Torres², and Emmanuel S. Pérez-Meléndez² \\ ${ }^{1}$ High specialty algology service; ${ }^{2}$ Department of anesthesiology, Hospital General de México "Dr. Eduardo Liceaga. Mexico City, Mexico
}

\begin{abstract}
Introduction: Magnesium sulfate heptahydrate (MgSO4 $7 \mathrm{H} 2 \mathrm{O})$ is a divalent cation, pharmacologically its mechanism has been as a reversible blocker of the N-methyl-D-aspartate receptor (NMDAR) and therefore has been proposed in the use of anesthesiology. Objective: to describe its properties, its mechanism of action, the uses and the doses in anesthesiology. Methodology: A bibliographic review was carried out with keywords: anesthesia, magnesium sulfate, analgesia, muscle relaxation and organ protection in: PubMed, Science Direct, Embase and Cochrane Library. The articles considered most relevant and with the greatest evidence were selected. Results: A total of 244 articles were obtained, 210 were eliminated, a total of 34 articles remained. The bibliography reports the use of $\mathrm{MgSO} 4 \mathrm{H} 2 \mathrm{O}$ as an adjunct in sedation, analgesia, neuromuscular relaxation, motor relaxation in neuraxial anesthesia, prophylaxis for postoperative nausea and vomiting, as well as in pathologies that require its application prevenient to or during the anesthetic event (alterations in serum levels of $\mathrm{Mg}^{++}$, patients with treatment based on MgSO4 7H2O, bronchospasm, hypertensive uncontrolled, excessive bleeding and cardiac arrhythmias). Conclusions: The use of MgSO4 $7 \mathrm{H} 2 \mathrm{O}$ has shown useful pharmacokinetic and pharmacodynamic qualities in the management of the surgical patient patient such as analgesia, sedation, hemodynamic stability, decrease in PONV and decrease in the consumption of opioids and hypnotics, and it can also be applied as treatment of the patient's own pathologies.
\end{abstract}

Keywords: Magnesium sulfate. Anesthesia. Analgesia. N-methyl-D-aspartate receptors.

\section{Introduction}

Magnesium $\left(\mathrm{Mg}^{++}\right)$is a divalent cation with a molecular weight of $24.303 u$, the fourth most abundant in the body and the second at the intracellular level. It comprises approximately $0.03 \%$ of total body weight $(99 \%$ intracellular and $1 \%$ extracellular), $95 \%$ is filtered in the glomerulus and $5 \%$ is excreted in feces ${ }^{1,2}$.

In the 1980s it was observed that physiological magnesium concentrations produce a reversible blockade of the N-methyl-D-aspartate (R-NMDA) receptor, playing a key role in cell activity, its main biochemical functions being: 1. - the synthesis and degradation of high-energy compounds by binding to adenosine triphosphate (ATP), forming a biologically active substrate
$\left[\mathrm{Mg}^{++}\right.$-ATP]; 2. - intervention in oxidative phosphorylation; 3.- the modulation of the transportation of ATP-dependent ions (sodium, potassium and calcium); 4. - it is a cofactor of more than 300 ATP-dependent enzyme systems; and 5. - in the cellular metabolism of carbohydrates, lipids and protein. The advancement of anesthesiology has seen enormous progress together with molecular biology, and magnesium sulfate (MgSO4) has been used in trans-anesthesia procedures as a sedative, analgesic and muscle relaxant, as well as an organ protector in different scenarios, for over 20 years $^{1,3}$. We have conducted a literature review with the aim of describing the properties of magnesium, its mechanism of action and the use thereof in anesthesiology in recent years.

\section{Correspondence:}

${ }^{*}$ Claudia I. Gutiérrez-Román

E-mail: claudiagtzr23@gmail.com

0185-1063/@ 2021 Sociedad Médica del Hospital General de Mexico. Published by Permanyer. This is an open access article under the CC BY-
Date of reception: 13-03-2021

Date of acceptance: 26-08-2021

DOI: 10.24875/HGMX.21000022
Available online: 07-03-2022

Rev Med Hosp Gen Mex. 2022;85(1):25-33 www.hospitalgeneral.mx NC-ND license (http://creativecommons.org/licenses/by-nc-nd/4.0/) 


\section{Methodology}

We conducted a literature review with the use of keywords (anesthesia, magnesium sulfate, analgesia, muscle relaxation and organ protection) using the PubMed, Science Direct, Embase and Cochrane Library search engines. We focused on meta-analyses, review articles and controlled trials, however we focused on controlled trials in the case of uses with little evidence. The articles were evaluated by 3 people, who conducted a summary of each one and filed them in a folder; the information was written up at a later date.

\section{Results}

A total of 244 articles were obtained, 210 of which were discarded due to being repetitive, irrelevant, trials with faulty methodologies or not directly applicable to the anesthesia process, leaving a total of 34 articles.

\section{Pharmacokinetics and pharmacodynamics}

The term Magnesium Sulfate has been used in the field of medicine in a popular manner, however, it should be pointed out that the real chemical name is magnesium sulfate heptahydrate (MgSO4 $7 \mathrm{H}_{2} \mathrm{O}$ ). $\mathrm{MgSO} 47 \mathrm{H} 2 \mathrm{O}$ is available in $10-\mathrm{ml}$ format and contains $1.5 \mathrm{~g}$ of $\mathrm{MgSO} 4$ and $150 \mathrm{mg}$ of $\mathrm{Mg}^{++}$(6 mmol or $\left.12 \mathrm{mEq}\right)$. $\mathrm{Mg}^{++}$is absorbed by the small intestine, particularly when administered orally. When administered intravenously (IV), it has an immediate onset of action, with a peak effect in 10 minutes and a length of action of 30 minutes; the intramuscular (IM) route is slower and reaches a peak of action at 60 minutes with a half-life of 4 hours. Another route of administration is through nebulisation as an adjuvant in asthma crises and more recently at the epidural level ${ }^{1,4}$.

- Distribution: $99 \%$ is intracellular (53\% to $60 \%$ is found in bone tissue, $20 \%$ to $27 \%$ in muscle tissue and $19 \%$ in soft tissue) and $1 \%$ is extracellular (60\% ionised, $30 \%$ protein-bound and $10 \%$ complex anions). At the intracellular level, it is found mainly in ionised form in ATP, cytoskeleton, nucleotides or enzyme complexes, leaving a very small portion in non-ionised form. Muscle cells, especially cardiac, have a higher concentration of intracellular $\mathrm{Mg}^{++}(11-17 \mathrm{mmol} / \mathrm{L})$. The tissue depositions of magnesium sulfate are stable and a balance will be reached by day 41 to 181 in the event of replenishment ${ }^{1,4}$.

- Elimination: mainly renal (80\%), $95 \%$ of which is reabsorbed (10-15\% in the distal contoured tube (DCT) and the rest in the loop of Henle), with only $3-5 \%$ being eliminated in urine. It can increase or decrease depending on the plasma concentrations of $\mathrm{Mg}^{++}$or certain medical conditions such as pre-eclampsia, where a decrease in clarity is observed before delivery compared to postpartum ${ }^{1,4}$.

With regard to pharmacodynamics, magnesium sulfate has multiple mechanisms of action, such as the activation of the sodium potassium ATPase pump, which can be inhibited in the presence of high concentrations of $\mathrm{Mg}^{++}$; competitive antagonism of calcium channels conferring the characteristic of blocking the release of presynaptic acetylcholine and increasing the threshold of postsynaptic action potential, blocking the release of catecholamines from the adrenal glands and adrenergic nerve terminals, as well as reducing the release of cytokines (IL-1, IL-6, TNF- $\alpha$ and substance P) and the inhibition of platelet aggregation; non-competitive antagonism of R-NMDA; sinusoidal and atrioventricular (AV) block, PR prolongation and QRS widening. Each of these is dose dependent, which involves a risk of toxicity at high doses s,2,4. $^{1}$.

As with other drugs, anesthesiologists should be fully familiar with $\mathrm{MgSO} 47 \mathrm{H} 2 \mathrm{O}$, as it needs to be administered with caution due to its pharmacological interactions. We should bear in mind that the anesthesiologist is in contact with all types of stable and critical patients (heart disease, pregnant women with pre-eclampsia or eclampsia, asthmatics, etc.), all of whose condition could worsen, exacerbate or who are undergoing an MgSO4 7H2O-based treatment on arrival; and all of them will need to continue to manage it or to start on it. $\mathrm{MgSO} 47 \mathrm{H} 2 \mathrm{O}$ features various pharmacological interactions that need to be taken into account by the anesthesiologist, including: 1.- interactions with other anesthetic drugs on reducing the consumption of hypnotics such as Sevofluorane and Propofol (its hypnotic properties could result in a reduction in the consumption of any hypnotic used in the trans-anesthetic, however there is no literature with regard to others), as well as demonstrating a synergistic effect with non-depolarising muscle relaxants (this is explained by a lower release of calcium); 2.- calcium is an antagonist of MgSO4 $7 \mathrm{H} 2 \mathrm{O}$ and is even used as a treatment in the event of poisoning; 3.- with antiarrhythmic drugs, a synergy with calcium channel blockers has been registered, which translates into a reduction in systemic blood pressure, likewise it reduces the serum levels of digoxin and increases the serum levels of quinidine; 4.- the use of diuretics such as thiazides promote the elimination of $\mathrm{MgSO} 47 \mathrm{H} 2 \mathrm{O}$; 5.- some antibiotic drugs are capable of increasing its clearance; 6.- some 
corticosteroids are capable of reducing the serum levels of $\mathrm{Mg}^{++}(\text {Table } 1)^{1}$.

\section{NMDA receptor}

In light of the various mechanisms of $\mathrm{Mg}^{++}$in our body and its participation in R-NMDA, this receptor, an ionotropic-type glutamate receptor, takes on significant importance. They have a heterotetrameric structure made up of three different subunits named GluN1-3, each of which has 4 transmembrane domains (M1-M4). The GluN1 subunit has eight isoforms, while GluN2 has four and GluN3 two. Functional NMDA receptors contain two binding subunits of GluN1 in combination with two subunits of GluN2 and/or GluN3 (Fig. 1) ${ }^{5}$.

The simultaneous presence of two different ligands is required to activate it. The $\mathrm{S} 1$ subunit provides the receptor with stability, while the $\mathrm{S} 2$ subunit enables it to bind to the ligand, the gate opens through the rotation and lateral movement of $M 3$, allowing for the entry of $\mathrm{Ca}^{++}$. The R-NMDA GluN1/GluN2 (the most abundant receptor) require two glycine molecules and two glutamate molecules, while the GluN1/GluN3 require glycine only in order to become activatived ${ }^{5}$.

Partial R-NMDA agonists and coagonists include: L-glutamate, D-glutamate, N-methyl-L-aspartate, D-aspartate and L-aspartate. Glutamate concentration determines the specific pattern of R-NMDA activation. Synaptically released glutamate reaches a cleft concentration peak of $1 \mathrm{~mm}$ and is then rapidly eliminated through diffusion and absorption, with a time constant of $1 \mathrm{~ms}$. Once the coagonists and agonists have bound, the ion channel opens selectively for cations (especially $\mathrm{Na}+, \mathrm{K}+$ and $\mathrm{Ca}^{++}$), however, it is 10 times more permeable to $\mathrm{Ca}^{++}$compared to $\mathrm{Na}$. Calcium is a key intracellular signaling molecule involved in many kinds of neural plasticity, but it is also a key mediator of excitotoxic cell death when present in excess;.

Finally, the antagonists of this receptor are entrusted with preventing the entry of $\mathrm{Ca}^{++}$to the cell; some of the antagonists used in anesthesiology for the treatment of pain are ketamine and magnesium. Magnesium has a high affinity to GluN1/GluN2A and GluN1/ GluN2B receptors, and intermediate affinity to GluN1/ GluN2C and GluN1/GluN2D receptors ${ }^{6}$. The initial justification for the use of this drug as an analgesic is that a Gabaergic polarisation occurs during the pain process; in other words, a greater amount of gamma-aminobutyric acid (GABA) is released, resulting in the the activation of its receptor (R-GABA) and reducing the release of glutamate and, therefore, its activation,
Table 1. Drug interactions

\begin{tabular}{|c|c|}
\hline Anesthetic drugs & $\begin{array}{l}\text { Adjuvant: reduces the consumption of } \\
\text { sevofluorane, propofol defluorane, } \\
\text { opioids and non-depolarising } \\
\text { neuromuscular relaxants }\end{array}$ \\
\hline Calcium & Magnesium antagonist \\
\hline Antiarrhythmic drugs & $\begin{array}{l}\text { Synergy with Ca+channel } \\
\text { blockers (responsible for the } \\
\text { antihypertensive effect) } \\
\text { Reduces serum digoxin levels } \\
\text { Increases serum quinidine levels }\end{array}$ \\
\hline Diuretics & $\begin{array}{l}\text { Thiazides increase the elimination } \\
\text { thereof }\end{array}$ \\
\hline Antibiotics & $\begin{array}{l}\text { Aminoglycosides and amphotericin B } \\
\text { increase the clearance thereof }\end{array}$ \\
\hline Corticoids & Prednisone reduces serum $\mathrm{Mg}^{++}$levels \\
\hline
\end{tabular}

Ca+: Calcium; $\mathrm{Mg}^{++}$: Magnesium.

thereby promoting a pro-inflammatory response. This is now being used as a basis for the treatment of both acute and chronic pain, demonstrating its sedative effect, as well as its various pharmacological actions (Table 2).

\section{The nervous system}

\section{Sedative and anticonvulsant}

$\mathrm{Mg}^{++}$produces an inhibitory effect on the neuron by blocking R-NMDA, which inhibits the entry of $\mathrm{Ca}^{++}$and prevents the release of other neurotransmitters, as well as activating neuronal apoptosis, hence it can be used as a sedative, anticonvulsant and neuroprotective. It has been shown to be effective in the prevention of seizures in patients with preeclampsia and pheochromocytoma, but not in other cases. Serum concentrations of between 2 and $3.5 \mathrm{mmol} / \mathrm{L}$ are generally regarded as therapeutic in pre-eclamptic patients. It is used to generate hypnosis and analgesia in anesthesia as it reduces the requirements for sevoflurane, defluorane, propofol and opioids. It is widely used in several different fields of medicine (neurology, pediatrics, gynecology, neuro-anesthesiology) due to its neuroprotective effect ${ }^{1,4,7-10}$.

\section{Analgesia}

$\mathrm{Mg}^{++}$can modulate the transmission of nociceptive stimuli and the perception of pain by blocking R-NMDA 


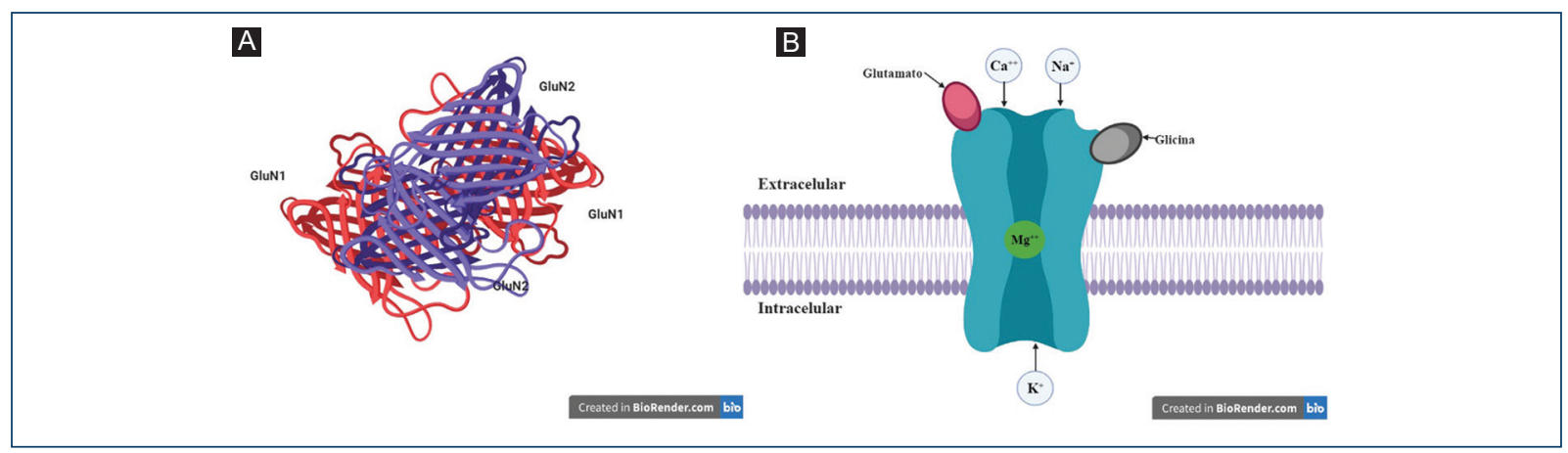

Figure 1. A: sub-units of the NMDA receptor. B: NMDA receptor; Glutamate, Glycine, extracellular, intracellular.

Table 2. Pharmacological effects of magnesium sulfate and uses in anesthesiology

\begin{tabular}{|c|c|c|}
\hline System & Pharmacological effect & Use in anesthesiology \\
\hline Nervous system & $\begin{array}{l}\text { Sedation } \\
\text { Analgesia (cerebral and neuraxial) } \\
\text { Cerebral vasoconstriction } \\
\text { Sympatholysis }\end{array}$ & $\begin{array}{l}\text { Hypnotic adjuvant (reduces PONV) } \\
\text { Analgesic } \\
\text { Neuroprotective in neurological surgery and in } \\
\text { patients with pre-eclampsia (prevents seizures) } \\
\text { Control of blood pressure }\end{array}$ \\
\hline $\begin{array}{l}\text { Muscles } \\
\text { - Cardiac } \\
\text { - Smooth } \\
\text { - Skeletal }\end{array}$ & $\begin{array}{l}\text { - Antarrhythmic Coronary vasodilation } \\
\text { - Pulmonary: bronchodilationVascular: } \\
\text { arterial vasodilationUterine: } \\
\text { tocolysis (should no longer be used for } \\
\text { this purpose) } \\
\text { - Relaxation }\end{array}$ & $\begin{array}{l}\text { Heart rate control } \\
\text { Cardioprotective } \\
\text { Bronchospasm (not first choice) } \\
\text { Control of blood pressure } \\
\text { Not applicable. } \\
\text { Adjuvant for non-depolarising muscle relaxants }\end{array}$ \\
\hline Metabolism & $\begin{array}{l}\text { Membrane stabilisation } \\
\text { Reduces oxidative damage by regulating } \\
\text { the Na-K-ATPase pump. }\end{array}$ & $\begin{array}{l}\text { Participates in analgesia and organ protection } \\
\text { Participates in analgesia, organ protection and } \\
\text { regulation of the inflammatory response }\end{array}$ \\
\hline Immune system & $\begin{array}{l}\text { Modulation of the immune response } \\
\text { - Hypermagnisemia: inhibits cytokine } \\
\text { release, risk of thrombosis. } \\
\text { - Hypomagnisemia: release of free } \\
\text { radicals, DNA mutations, risk of bleeding. } \\
\text { Platelet anti-aggregant at high doses }\end{array}$ & $\begin{array}{l}\text { Modulates the inflammatory response } \\
\text { Possible increase in cardiovascular risk } \\
\text { Possible increase in surgical stress, inflammatory } \\
\text { response, and risk of intra-operative bleeding } \\
\text { Possible reduction in thrombotic effects }\end{array}$ \\
\hline
\end{tabular}

PONV: post-operative nausea and vomiting; ATP: adenosine triphosphate; DNA: deoxyribonucleic acid.

and $\mathrm{Ca}^{++}$channels in the central nervous system, regulating the release of neurotransmitters in the brain and spinal cord. More specifically, $\mathrm{Mg}^{++}$has a depressant effect on the release of catecholamine in adrenergic nerve endings, the spinal cord and adrenergic sympathetic postganglionic fibers. Clinical trials have registered its use in bolus, and/or intravenous, intra-articular infusion, as an adjuvant in regional anesthesia, total intravenous, epidural and intrathecal anesthesia1 ${ }^{1,11 .}$

The infusion of a low dose of $10-15 \mathrm{mg} / \mathrm{kg} / \mathrm{hour}$ leads to an improvement in postoperative pain scores from 6 hours to 3 days post-surgery, thereby reducing the requirement for opioids. Intravenous $\mathrm{MgSO} 47 \mathrm{H} 2 \mathrm{O}$ can speed up the onset and prolong the duration of sensory block, motor block, relieve post-operative pain, without any additional side effects and without speeding up the onset of motor block in preeclamptic women undergoing spinal anesthesia. Compared to drugs such as dexmedetomidine, $\mathrm{Mg}^{++}$does not cause reflex tachycardia or secondary hypotension when used as a hypotensive agent in the intra-operative period; does not produce reflex hypertension, and does not reduce cardiac output. While dexmedetomidine is associated more with bradycardia, although it is the ideal drug for controlled hypotension and provides better visibility in laparoscopic surgery. Several studies support the analgesic effect of $\mathrm{Mg}^{++}$in orthopedic, cardiac, abdominal and otorhinolaryngological surgery, with a reduction in the 
requirement fo opioids, mainly alfentanil, fentanyl, morphine and remifentanil. It has been used as a drug in controlled hypotension. It has also been used during neuraxial block, where "it prolongs the duration of motor block and sensory block, increases the onset interval of motor block and sensory block when administered via the subarachnoid route and reduces it when administered via the epidural route"7,12-18.

MgSO4 $7 \mathrm{H} 2 \mathrm{O}$ is not classified as an antiemetic, however, it should be regarded as a prophylactic for postoperative nausea and tremors, as this characteristic is acquired by reducing the consumption of opioids. It should be pointed out that no mechanism of action directly related to the regulation of the nauseous centre has been discovered to date ${ }^{1,4,14}$.

\section{Muscle relaxant}

The reduction in intracellular $\mathrm{Ca}^{++}$delays vesicular transport, in such a way that the presynaptic release of acetylcholine is lower, thereby increasing the postsynaptic depolarisation threshold, which translates into muscle relaxation. When used in anesthesia, this characteristic reduces the onset time, intubation doses, the requirement for non-depolarising muscle relaxants, and increases the duration of the subrachnoid block $^{1,4,18}$.

MgSO4 $7 \mathrm{H} 2 \mathrm{O}$ functions as a negative inotropic in the cardiac musculature, prolonging the conduction time associated with its calcium-antagonist properties, preventing it from binding to myocyte troponin $\mathrm{C}$. Its antiarrhythmic effect can be explained by sinus node (SN) depression by prolonging conduction and the AV refractoriness time, without altering the ventricular function. Magnesium bolus therapy after cardiac surgery has been shown to lead to a significant but brief increase in serum $\mathrm{Ca}^{++}$. In smooth muscle, $\mathrm{Ca}^{++}$inhibition leads to mainly arteriolar vasodilation, although it has also been associated with a reduction in angiotensin converting enzyme (ACE). The use of MgSO4 $7 \mathrm{H} 2 \mathrm{O}$ in the intraoperative phase of abdominal, orthopedic and urological surgery in patients diagnosed with grade 1 and 2 arterial hypertension registered greater hemodynamic stability after 60 minutes of anesthesia ${ }^{1,2,16}$.

MgSO4 $7 \mathrm{H} 2 \mathrm{O}$ is also beneficial to the muscles when used a bronchodilator in refractory asthma. It is important to remember that it shouldn't be used as the only treatment in such patients. It has been shown that the combination of nebulised $\mathrm{MgSO} 47 \mathrm{H} 2 \mathrm{O}$ + salbutamol can effectively improve forced expiratory volume in 1 second (FEV1) in children with bronchial hyperresponsiveness compared to the exclusive use of nebulised $\mathrm{MgSO} 47 \mathrm{H} 2 \mathrm{O}$ at 10 minutes and 20 minutes. MgSO4 7H2O, due to its relaxing, spasmolytic and anti-inflammatory properties, reduces coughing, bronchial hyperresponsiveness and bronchospasm during extubation. Indeed, it has been shown that patients receiving topical $\mathrm{MgSO} 47 \mathrm{H} 2 \mathrm{O}$ prior to intubation undergo less post-operative throat pain and swelling, as well as less hoarseness; this effect is even better than that registered with the use of lidocaine or ketamine and similar to the use of corticosteroids ${ }^{1,19,20}$.

In times gone by, MgSO4 $7 \mathrm{H} 2 \mathrm{O}$ was used as a tocolytic treatment in premature labour; however we now know it is of no use in such cases. Nevertheless, it should be taken into account that the recommended serum concentration to achieve the desired effect in pre-eclamptic patients is $4.8 \mathrm{mg} / \mathrm{dL}$ and that its use as a tocolytic has now been ruled out, as it has proven to be ineffective in these cases ${ }^{1,19,20}$.

\section{Organ protection}

$\mathrm{Mg}^{++}$is entrusted with maintaining adequate intracellular ATP levels; inhibits intracellular influx and accumulation of $\mathrm{Ca}^{++}$(blocking the "R-NMDA" calcium channels). This prevents the release of pro-inflammatory cytokines and the formation of free radicals, thereby reducing edema and oxidative cell damage. With regard to the neuroprotective activity of $\mathrm{Mg}^{++}$in patients with hemorrhagic CVD undergoing neurosurgery, despite the fact that several studies have registered adequate efficacy, a meta-analysis conducted in 2015 demonstrated a lack of evidence to support the use of MgSO4 $7 \mathrm{H} 2 \mathrm{O}$ as a neuroprotective, however, it is still the main treatment for the prevention of seizures in patients with pre-eclampsia in the field of obstetrics. At the cardiac level, it has been described as an efficient drug for the prevention of arrhythmias in both cardiac and non-cardiac surgery ${ }^{1,23,24}$.

MgSO $47 \mathrm{H} 2 \mathrm{O}$ has also been used to limit the hypertensive response during intubation by controlling the hypertensive crisis during pheochromocytoma surgery; patients diagnosed with arterial hypertension as it decreases the mean arterial pressure (MAP) under general anesthesia, reducing the heart rate $(\mathrm{HR})$ and, therefore, bleeding ${ }^{12-15}$.

\section{Coagulation}

The importance of $\mathrm{Ca}^{++}$in coagulation has been widely documented. $\mathrm{Mg}^{++}$, by acting on R-NMDA, is involved in free $\mathrm{Ca}^{++}$levels and therefore tends to 
alter the state of coagulation. It has been shown that patients with type-2 diabetes mellitus are more prone to coagulopathies with a reduced partial thromboplastin time, lower serum $\mathrm{Mg}^{++}$levels, an increased prothrombin time and high ionised calcium levels. Moreover, $\mathrm{Mg}^{++}$intake has been associated with being a preventive factor in thrombotic events, whereby the risk of stroke is reduced by $2 \%$ for each $100 \mathrm{mg} /$ day increase in magnesium. Furthermore, the intra-operative administration of intravenous magnesium sulfate reduces blood hypercoagulability in patients undergoing laparoscopic surgery for colorectal cancer. Aravidan et al 2016 illustrated a reduction in bleeding and a better surgical field in patients undergoing functional endoscopic sinus surgery under total intravenous anesthesia upon the administration of MgSO4 $7 \mathrm{H} 2 \mathrm{O}$. The trials published to date on the use of $\mathrm{MgSO} 47 \mathrm{H} 2 \mathrm{O}$ and its role in the prevention of coagulopathy in the trans-anesthetic period have yielded positive results, however, we still have insufficient evidence ${ }^{26-29}$

\section{Immune system}

The participation of $\mathrm{Mg}^{++}$in the immune system is impressive; a large amount of this mineral is capable of blocking $\mathrm{Ca}^{++}$channels and reducing their concentration, thereby delaying the vesicular migration of various molecules such as interleukins, and reducing the inflammatory response. Moreover, $\mathrm{Mg}^{++}$ions are enzymatic cofactors involved in deoxyribonucleic acid (DNA) repair mechanisms that ensure stability and genomic fidelity. Magnesium deficiency can also be associated with inflammation and increased levels of free radicals capable of causing oxidative damage to DNA and promoting the presence of cellular mutations, and a higher expression of magnesium transport channels has been observed in tumorous breast cancer cells, which increases the intracellular concentration of the mineral, thereby contributing to tumour growth through its function of increasing energy demand. This data, however, is scarce and inconsistent ${ }^{29,30}$.

This leads us to consider whether or not the use of $\mathrm{MgSO} 47 \mathrm{H} 2 \mathrm{O}$ is appropriate in cancer surgery. In this regard, it has been shown, as in other surgeries, to be effective in reducing opioid consumption, as well as in post-operative algological control, nausea and vomiting, waking up with no anxiety, and less bleeding, all of which with no changes in serum $\mathrm{Mg}^{++}$levels, in gastric and abdominal cancer surgery, pituitary adenoma, among others. In addition, MgSO $47 \mathrm{H} 2 \mathrm{O}$ is used in opioid-free anesthesia, where cancer patients are among the few indications. Nevertheless, up to now there is no evidence that it is more effective than ketamine, dexmedetomidine or even lidocaine pursuant to the evidence on the use thereof in this patient group ${ }^{31-33}$.

\section{Hypo and hypermagnesemia}

Serum $\mathrm{Mg}^{++}$levels are measured in the pre-anesthetic examination, paying special attention to patients with pathologies associated with hypo or hypermagnesemia, as irregular levels could be associated with trans-anesthetic complications and even death. It is of paramount importance that the anesthesiologist is familiar with the normal levels of serum $\mathrm{Mg}^{++}$and is capable of recognising the symptoms associated with variations in these levels (Table 3 ).

Hypermagnesemia can occur in chronic infectious diseases, diabetic ketoacidosis, Addison's disease, atherosclerosis, and in chronic kidney failure. Hypermagnesemia can also be iatrogenic, although such cases are usually very rare. The use of $\mathrm{MgSO} 47 \mathrm{H} 2 \mathrm{O}$ infusions has shown an increase in $\mathrm{Mg}^{++}$of up to $3 \mathrm{mg} / \mathrm{dL}$ with no symptoms, while infusions used in obstetrics register a plasma concentration close to the therapeutic values for preeclamptic patients $(1.7 \mathrm{mmo} / \mathrm{L})^{9,34}$.

Hypomagnesemia is often associated with prolonged diarrhea, prolonged diuretic therapy, malabsorption syndrome, hyperaldosteronism and alcoholism ${ }^{2} . \mathrm{Mg}^{++}$deficiency prevents the ATPase and free $\mathrm{Ca}^{++}$pump from functioning, causing stiffness, causing muscle relaxation. Although it is theoretically correct to say that the requirement for non-depolarising neuromuscular relaxants may be higher during the trans-anesthetic period, there are no studies in this regard. Plasma concentrations below $0.7 \mathrm{mmol} / \mathrm{L}$ are regarded as Hypomagnesemia, while levels below 0.5 $\mathrm{mmol} / \mathrm{L}$ are regarded as a serious condition. It has been documented that post-operative patients admitted to the ICU may suffer from hypomagnesemia, which involves a higher mortality rate $(41 \% \times 13 \%$ in patients with normal levels). Initial management should be geared to respiratory and hemodynamic support (if necessary) and the administration of magnesium should be started with $60-100 \mathrm{mg} / \mathrm{kg}$ of calcium gluconate or $20-30 \mathrm{mg} / \mathrm{kg}$ of calcium chloride, hydration, $1-2 \mathrm{mg} / \mathrm{kg}$ of furosemide, in addition to hemodialysis ${ }^{1,4,34}$. 
Table 3. Levels of plasma $\mathrm{Mg}^{++}$and symptoms

\begin{tabular}{|c|c|c|}
\hline & Plasma levels & Symptoms \\
\hline Severe hypomagnesemia & $\leq 1 \mathrm{mg} / \mathrm{dL}$ or $0.5 \mathrm{mmol} / \mathrm{L}$ & $\begin{array}{l}\text { Seizures, tetany, arrhythmias (ventricular extrasystoles, } \\
\text { ventricular tachycardia, ventricular fibrillation, } \\
\text { predisposition to digitalis toxicity), hypocalcemia. }\end{array}$ \\
\hline Mild hypomagnesemia & $\leq 1.6 \mathrm{mg} / \mathrm{dL}$ or $0.8 \mathrm{mmol} / \mathrm{L}$ & $\begin{array}{l}\text { Parasia, shaking, paresthesias, positive Chevosteck and } \\
\text { trousseau signs, carpal pedal spasms, nystagmus, } \\
\text { hyperreflexia, QT interval prolongation. }\end{array}$ \\
\hline Normal & 1.7 to $2.2 \mathrm{mg} / \mathrm{dL}$ or 0.85 to $1.10 \mathrm{mmol} / \mathrm{L}$ & Asymptomatic \\
\hline Mild & $3-4 \mathrm{mg} / \mathrm{dL}$ or $1.5-2 \mathrm{mmol} / \mathrm{L}$ & $\begin{array}{l}\text { Nausea, vomiting, dizziness, headache, lethargy, } \\
\text { hyporeflexia, hypotension and first-degree AV block }\end{array}$ \\
\hline Serious & $10-12 \mathrm{mg} / \mathrm{dL}$ or $5-6 \mathrm{mmol} / \mathrm{L}$ & $\begin{array}{l}\text { Flaccid paralysis, coma, respiratory depression, complete } \\
\text { AV block and/or asystole }\end{array}$ \\
\hline
\end{tabular}

$\mathrm{Mg}^{++}$: magnesium; mg: milligram; dL: deciliter; L: liter; AV: atrioventricular.

Table 4. Reported doses of $\mathrm{MgSO} 4 \mathrm{7H} 2 \mathrm{O}$ in various scenarios

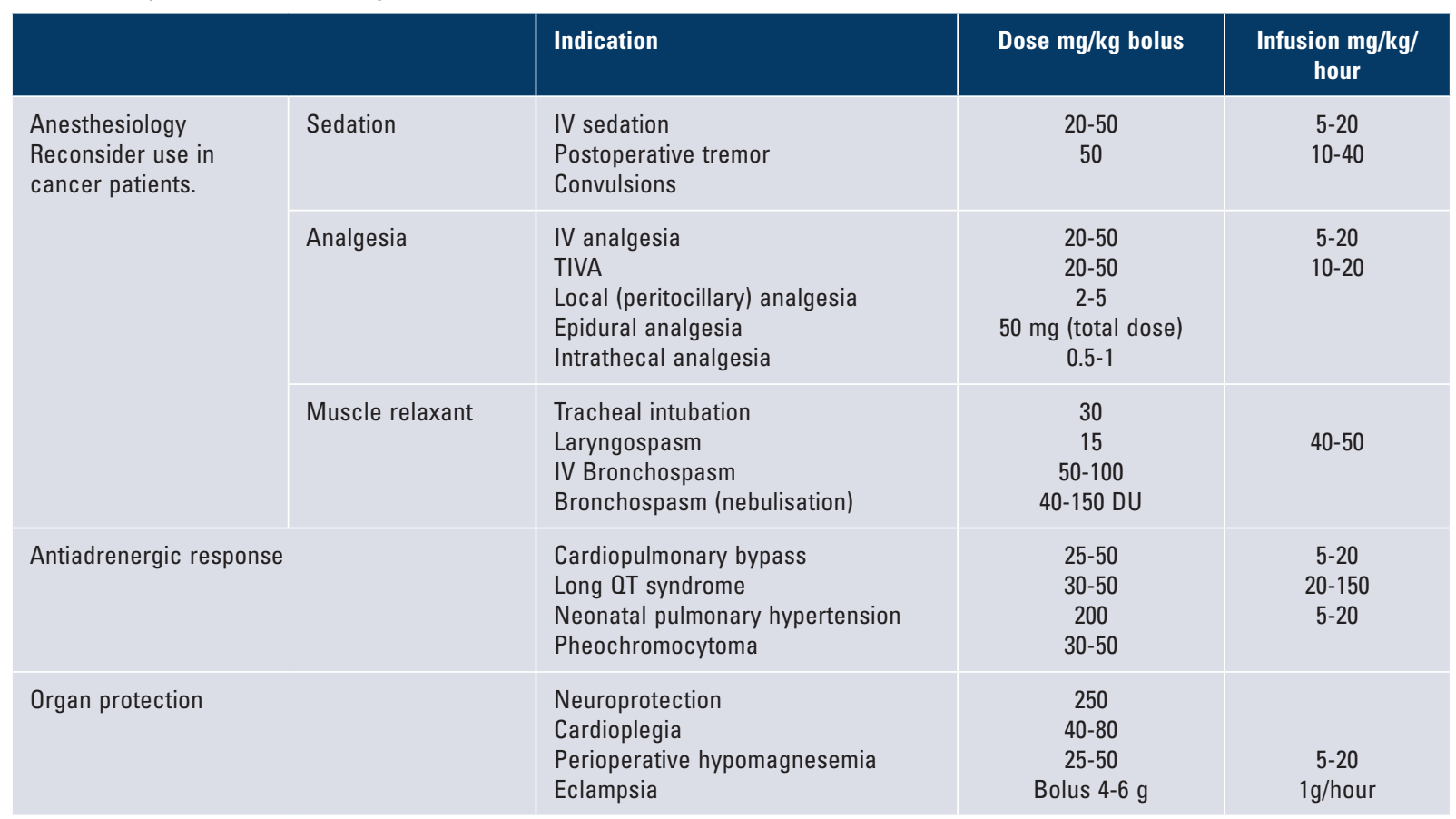

MgS04 7H2O: magnesium sulfate heptahydrate; IV: intravenous; TIVA: total intravenous anesthesia; g: gram; mg: milligram; hr: hour.

\section{Discussion}

There is extensive literature on the use of MgSO4 7H2O in anesthesiology where it is used as an adjuvant in sedation, analgesia, neuromuscular relaxation, motor relaxation in neuraxial anesthesia, a prophylactic for post-operative nausea and vomiting in practically all kinds of surgery, whereby it reduces the consumption of hypnotics and analgesics. It has the same results in cancer surgery, although the implications of the specific mutations of each tumour that could be promoted by $\mathrm{Mg}^{++}$are still unknown. Unfortunately, the level of evidence has not yet been determined and this is largely due to the lack of studies in this regard.

The anesthesiologist is also entrusted with taking care of patients with pathologies that interfere with levels of $\mathrm{Mg}^{++}$and which could undergo complications in 
the trans-anesthetic period; nevertheless, the use of $\mathrm{MgSO} 47 \mathrm{H} 2 \mathrm{O}$ in the field of medicine is widespread, which is why patients arriving with an infusion of this drug can be accepted, particularly in the case of pre-eclamptic patients, where it is used as a neuroprotective, with the requirement of therapeutic plasma concentrations, meaning the partial or permanent suspension thereof in the trans-anesthesia period is not recommended, and such treatment can be initiated if the patient isn't receiving it. Despite the fact it interacts with non-depolarising relaxants, there is no association between residual relaxation and patients with an infusion of $\mathrm{MgSO} 4 \mathrm{7H} 2 \mathrm{O}$, although this data is still inconsistent and the area needs to be studied ${ }^{10}$.

Anesthesiologists are not only entrusted with caring for healthy patients and scheduled surgery, but their extensive work includes caring for patients with pathologies that may be associated with irregular levels of serum $\mathrm{Mg}^{++}$, patients that are undergoing an $\mathrm{MgSO} 47 \mathrm{H} 2 \mathrm{O}-$ based treatment upon arrival, and which needs to be continued or started. Finally, anesthesiologists have to deal with complications in the trans-anesthesia period, where $\mathrm{MgSO} 47 \mathrm{H} 2 \mathrm{O}$ can be used, such as bronchospasms (both in patients with a history of asthma history and apparently healthy patients), uncontrolled hypertension, excessive bleeding and cardiac arrhythmias.

The intravenous dose schemes are 25 to $50 \mathrm{mg} / \mathrm{kg}$ followed by an infusion of 6 to $25 \mathrm{mg} / \mathrm{kg} /$ hour (Table 4), with the exception of the Zuspan scheme, a model dating back to 1985 used in obstetrics for the management of pre-eclamptic patients, in which a bolus dose of $4 \mathrm{~g}$ over 30 minutes is standard, followed by an infusion of $1 \mathrm{~g} /$ hour, which has been shown to be effective in preventing seizures, but has not reached the therapeutic doses specified. Experts describe this scheme as safe and effective, which is why they highlight the importance of basing treatment on this scheme and not on reaching the therapeutic levels, which reduces the risk of secondary toxicity data ${ }^{7,9}$.

\section{Conclusions}

The use of MgSO4 7H2O has positive pharmacokinetic and pharmacodynamic properties for use in anesthesiology, and more specifically it has shown various qualities in the management of surgery patients such as analgesia, sedation, hemodynamic stability, reduced PONV and a reduced consumption of opioids and hypnotics. However, the use of $\mathrm{MgSO} 47 \mathrm{H} 2 \mathrm{O}$ beyond this area is not limited and it can also be used to treat patient-specific pathologies.

\section{Acknowledgements}

At the anesthesiology service of the Hospital General de México "Dr. Eduardo Liceaga" for promoting the investigation.

\section{Funding}

The authors received no financial support for the research, authorship, and/or publication of this article.

\section{Conflict of interest}

The authors declared no potential conflicts of interest with respect to the research, authorship, and/or publication of this article.

\section{Ethical disclosures}

Protection of human and animal subjects. The authors declare that no experiments were performed on humans or animals for this study.

Confidentiality of data. The authors declare that they have followed the protocols of their work center on the publication of patient data.

Right to privacy and informed consent. The authors declare that no patient data appear in this article.

\section{References}

1. Eizaga Rebollar R, García Palacios M V, Morales Guerrero J, Torres LM. Magnesium sulfate in pediatric anesthesia: the Super Adjuvant. Paediatr Anaesth. 2017;27(5):480-9.

2. Vicković S, Pjević M, Uvelin A, Pap D, Nikolić D y Lalić I. Magnesium Sulfate As an Adjuvant To Anesthesia in Patients With Arterial Hypertension. Acta Clin Croat. 2016;55(3):490-6.

3. Turnbull D. Magnesium: Looking for a role in anesthesia. Minerva Anestesiol. 2015;81(11):1156-8.

4. Rodríguez-Rubio L, Solís-García Del Pozo J, Nava E, Jordán J. Interaction between magnesium sulfate and neuromuscular blockers during the perioperative period. A systematic review and meta-analysis. J Clin Anesth. $2016 \mathrm{Nov} ; 34: 524-34$.

5. Vyklicky V, Korinek M, Smejkalova T, et al. LV. Structure, function, and pharmacology of NMDA receptor channels. Physiol Res. 2014;63(1):S191-203.

6. Glasgow NG, Siegler Retchless B, Johnson JW. Molecular bases of NMDA receptor subtype-dependent properties. J Physiol. 2015;593(1):83-95.

7. Rodríguez-rubio L, Nava E, Solís J, Jordán J. In fl uence of the perioperative administration of magnesium sulfate on the total dose of anesthetics during general anesthesia. A systematic review and meta-analysis. J Clin Anesth. Elsevier Inc.; 2017;39:129-38.

8. Lingam I, Robertson NJ. Magnesium as a Neuroprotective Agent: A Review of Its Use in the Fetus, Term Infant with Neonatal Encephalopathy, and the Adult Stroke Patient. Dev Neurosci. 2018;40(1):1-12.

9. Olgun B, Oguz G, Kaya M, et al, KN. The effects of magnesium sulphate on desflurane requirement, early recovery and postoperative analgesia in laparoscopic cholecystectomy. Magnes Res. 2012;25:72-8.

10. Okusanya BO, Oladapo OT, Long Q, et.al. GAM. Clinical pharmacokinetic properties of magnesium sulphate in women with pre囚eclampsia and eclampsia. BJOG. 2016 Feb; 123(3): 356-366.

11. Silva Filho SE, Sandes CS, Vieirac JE, Cavalcanti IL. Analgesic effect of magnesium sulfate during total intravenous anesthesia: randomized clinical study. Brazilian Journal of Anesthesiology. 2010. Rev virtual. https:// doi.org/10.1016/j.bjane.2021.02.0 


\section{C.I. Gutiérrez-Román et al.: Uses of magnesium sulfate in anesthesiology}

12. Akkaya A, Tekelioglu UY, Demirhan A, et al, KH. Comparación de los efectos de sulfato de magnesio y dexmedetomidina sobre la calidad de la visibilidad en cirugía endoscópica sinusal: estudio clínico aleatorizado. Brazilian J Anesthesiol. Sociedad Brasileira de Anestesiologia 2014;64(6):406-12

13. Haryalchi K, Abedinzade M, Khanaki K, Mansour Ghanaie M, Mohammad Zadeh F. Por qué la infusión preventiva de una dosis baja de sulfato de magnesio influye en la percepción del dolor postoperatorio y el nive sérico de beta-endorfinas en las histerectomías abdominales totales. Rev Esp Anestesiol Reanim. 2017;64(7):384-90.

14. Zhong HY, Zhang WP. Effect of intravenous magnesium sulfate on bupivacaine spinal anesthesia in preeclamptic patients. Biomed Pharm. 2018;108:1289-93.

15. Castro J, Cooney MF. Intravenous Magnesium in the Management of Postoperative Pain. J Perianesth Nurs. Elsevier Inc; 2017;32(1):72-6.

16. Biesenbach $P$, Mårtensson J, Lucchetta L, et al, BR. Pharmacokinetics of Magnesium Bolus Therapy in Cardiothoracic Surgery. J Cardiothorac Vasc Anesth 2018;32(3):1289-94.

17. Lang B, Zhang L, Lin Y, Zhang W, Li FS, Chen S. Comparison of effects and safety in providing controlled hypotension during surgery between dexmedetomidine and magnesium sulphate: A meta-analysis of randomized controlled trials. PLoS ONE 15(1): e0227410.

18. Rusz Ahuad Cl. Hernández Hernández FJ, Torres González CA, García Mora MA. El uso de sulfato de magnesio como adyuvante en el bloqueo regional neuroaxial. Metaanálisis. Acta Médica Grupo Ángeles. 2020; 18 (2): 156-171

19. Wang H, Xiong Y, Gong C, et al, DJ. Effect of Inhaled Magnesium Sulfate on Bronchial Hyperresponsiveness. Indian J Pediatr. 2015;82(4):321-7.

20. Kuriyama A, Maeda $H$ y Sun R. Topical application of magnesium to prevent intubation-related sore throat in adult surgical patients: a systematic review and meta-analysis. Can J Anesth. 2019;66(5):562-75.

21. Brookfield KF, Su F, Elkomy MH, Drover DR, Lyell DJ, Carvalho B. Pharmacokinetics and placental transfer of magnesium sulfate in pregnant women. Am J Obstet Gynecol. Elsevier Ltd; 2016;214(6):737.e1-737.e9.

22. Hanley M, Sayres L, Reiff ES, Wood A, Grotegut CA, Kuller JA. Tocolysis: A Review of the Literature. Obstet Gynecol Surv. 2019;74(1):50-5.

23. Riaz N, Wolden SL, Gelblum DY, Eric J. Cerebral protection during neurosurgery and stroke. 2016;118(24):6072-8.
24. Cox AG, Marshall SA, Palmer KR y Wallace EM. Current and emerging pharmacotherapy for emergency management of preeclampsia. Expert Opinion on Pharmacotherapy, 20:6, 701-712.

25. McKeown A, Seppi V, Hodgson R. Intravenous Magnesium Sulphate for Analgesia after Caesarean Section: A Systematic Review. Anesthesiol Res Pract. 2017;2017:1-9.

26. Ephraim RK, Awuku YA, Adu $\mathrm{P}$, et al, AH. High risk of coagulopathy among Type-2 Diabetes Mellitus clients at a municipal hospital in Ghana. Ghana Med J. 2017;51(3):101-7.

27. Zhao B, Hu L, Dong $Y$, et al, Zhang $W$. The effect of magnesium intake on stroke incidence: A systematic review and meta-analysis with trial sequential analysis. Front Neurol. 2019; 10:852.

28. Na HS, Shin HJ, Kang SB, Hwang JW, Do SH. Effects of magnesium sulphate on coagulation after laparoscopic colorectal cancer surgery, measured by rotational thromboelastometry (ROTEM). Anaesthesia. 2014:69(12):1314-21.

29. Livingstone M, Duttchen K, Thompson J, et al, PJ. Hemodynamic Stability During Pheochromocytoma Resection: Lessons Learned Over the Last Two Decades. Ann Surg Oncol. 2015;22(13):4175-80.

30. Mendes PMV, Bezerra DLC, dos Santos LR, et al, Marreiro DN. Magnesium in Breast Cancer: What Is Its Influence on the Progression of This Disease?. Biol Trace Elem Res. 2018;184(2):334-9.

31. Kim MH, Lee KY, Park S, Kim S II, Park HS, Yoo YC. Effects of systemic lidocaine versus magnesium administration on postoperative functional recovery and chronic pain in patients undergoing breast cancer surgery: A prospective, randomized, double-blind, comparative clinical trial. PLoS One. 2017;12(3):1-13.

32. Gupta S, Sharma R, Dimpel J. The effects of dexmedetomidine and magnesium sulphate in adult patients undergoing endoscopic transnasal transsphenoidal resect of pituitary adenoma: A double-blind randomised study. Indian J Anaesth. 2014;49(4):257-62.

33. Wu L, Huang $X$, Sun L. The efficacy of N-methyl-D-aspartate receptor antagonists on improving the postoperative pain intensity and satisfaction after remifentanil-based anesthesia in adults: A meta-analysis. J Clin Anesth. 2015;27(4):311-24.

34. Soave P, Conti G, Costa R, Arcangeli A. Magnesium and Anaesthesia. Curr Drug Targets. 2009;10(8):734-43. 